\title{
World Federation of Neurology: Moving into the Future
}

Can J Neurol Sci. 2013; 40: 609-611

Global neurology is coming of age and the World Federation of Neurology (WFN) is at its core. Founded in 1957, it has grown to encompass 114 national neurological societies.

\section{Congresses}

The author's first official involvement with the WFN was accidental. He was attending the World Congress of Neurology in New Delhi in 1989 and was summoned urgently by Donald Paty, President of the Canadian Neurological Society because the Canadian Delegate to the World Federation of Neurology, Andrew Kertesz, was coming to New Delhi via London, UK. There was a bomb threat, the flight was delayed and he would not arrive in time to pitch Canada's bid to become the host of the World Congress of Neurology in Vancouver in 1993. The author was named the Delegate and on short notice had to prepare a presentation to persuade the Delegates that among the several bidding cities, that Vancouver was the most worthy. The newly minted Canadian Delegate said "Vancouver is a spectacular city, nestled between the mountains and the sea, with a thriving neurological community and boasting ultramodern facilities... ..in 1492 Columbus discovered the Americas. We invite you to rediscover the Americas through Vancouver in 1993". We succeeded on the first ballot and Don Paty and his helpers put on an exemplary World Congress of Neurology with the honorary Presidency of Henry J.M. Barnett and with Lord Walton of Detchant as the President of the World Federation of Neurology.

Subsequently, the author was named Chairman of the Steering Committee of the WFN and in 2005 was elected Vice President. In that capacity he wrote a white paper arguing for moving the World Congress of Neurology from a four year cycle to a two-year cycle on the grounds that the most important impact of a world congress is not on those who usually attend the meetings and can travel anywhere in the world, but rather those who cannot travel internationally and can only attend if it is in their country or region. The idea of moving it to a two year cycle also meant that we could go more often to places in the world where there is a great need for neurology to thrive. This was not an easy task, since it meant the departure from a long and successful tradition, however, with persistence, the policy was approved. This has turned out to be a good decision, given that in addition to being able to go to different parts of the world and have a greater impact, the two year cycle offers continuity and smooth transition between congresses and we are able to have activities at a much higher intensity than was possible when the highlights of the WFN were congresses held every four years.

Moving to a two year cycle allowed for the author's predecessor as President, Johan Aarli's dream of holding the first World Congress of Neurology on the African continent, which took place in Marrakesh in October 2011. We made provisions for $20 \%$ of the revenues to be reinvested in activities in Africa and any African resident, trainee or faculty member from sub
Saharan African who asked for a travel scholarship obtained it. Additionally our Moroccan colleagues made special arrangements for affordable housing for colleagues from sub Saharan Africa.

The next Congress will take place in Vienna, September 2126,2013 . The fact that there is only a two year interval between the Congress in Marrakesh and Vienna has allowed for continuity and efficiency that was very difficult to obtain when the congresses were every four years and as a result there is more consistency in the organization and it also allows us to vary the themes. Certain topics are emphasized every two years, so that if any neurologist wanted to have one stop shopping for updating himself or herself in a field, then this is the best venue to do so. We make a special point of inviting distinguished individuals who are known not only for their knowledge in their field, but for their ability to convey it, since we are very conscious of the fact that the vast majority of our constituents do not have English as their primary language. We have also made sure that relevant aspects of basic science are covered as part of our broad understanding of our specialty. The Congress will also feature a rich array of teaching courses, seminars, symposia and hands-on workshops.

The theme of the Congress is "Neurology in the age of globalization". The Presidential session will address global neurology and in WFN's ever growing role in advancing a world brain agenda, Eric Kandel, the Noble Prize winner and native of Vienna will be a special speaker talking about aspects of his recent book "The Age of Insight: The Quest to Understand the Unconscious in Art, Mind, and Brain, from Vienna 1900 to the Present". Another unique feature of the Congress is that several of the sessions are co-sponsored with a subspecialty organization such as the International League of Epilepsy, the World Stroke Organization and the Movement Disorder Society. Under the leadership of Professor Eduard Auff, the Congress will offer a splendid social and cultural program in unique settings and unforgettable activities. (Figure 1)

\section{Mission}

In 2009 the author was elected President on the platform of continuity and change. The first step of the new administration was to redefine our mission. We enlarged it "to foster quality neurology and brain health worldwide". Clearly this mandate takes it beyond the confines of our specialty and requires that we reach out to other brain organizations. The first opportunity to act on the larger agenda occurred with the decision of the United Nations General Assembly to make non-communicable diseases a priority. Most neurological diseases fall to in this category hence on March 30, 2011 the author organized a meeting in Geneva that invited leaders from all the major brain organizations to work together. The World Brain Alliance (WBA) ended up having a membership of ten organizations: 


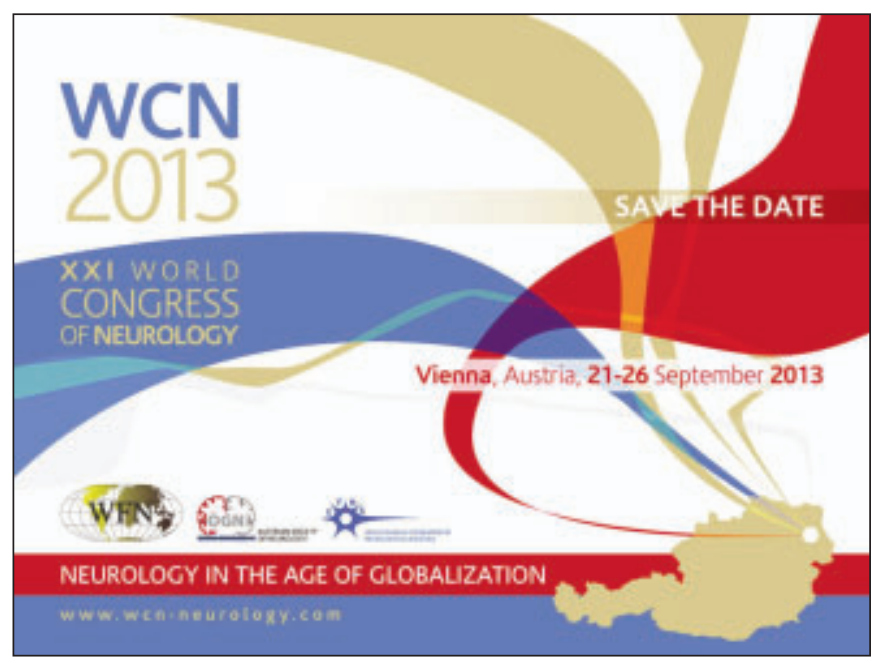

Figure 1: World Congress of Neurology 2013 advertisement.

Alzheimer's Disease International (ADI)

European Brain Council (EBC)

International Brain Research Organization (IBRO)

International Child Neurology Association (ICNA)

International League against Epilepsy (ILAE)

World Federation of Neurorehabilitation (WFNR)

World Federation of Neurology (WFN)

World Federation Neurosurgical Societies (WFNS)

World Psychiatry Association (WPA)

World Stroke Organization (WSO)

The $\mathrm{ABC}$ of the WBA is Advocacy, Brain year, Collaborations.

\section{Advocacy}

The author felt it was important that if we were going to have an influence on the United Nations agenda, then we should begin by working through the World Health Organization (WHO).

The author attended a high level ministers meeting in Moscow in April of 2011 that featured a "mystery guest" (Vladimir Putin) and meetings at the United Nations, for consultation with the President of the General Assembly (June 2011) and subsequently at the time of adoption of the resolution on non-communicable diseases in September 2011. The work continues, and we are emphasizing the three premises of the WBA:

1) There is no health without brain health;

2) Brain health and health begin with the mother's and the

child's and their education and

3) Our brains are our future $(C)$

We continue to advance the message where we can, including the World Health Assembly in May of 2012 and the Executive of the WHO earlier this year. (Figure 2)

The WFN and the WHO have a close working relationship. Johan Aarli (Norway) past President wrote and co-edited documents, books and an atlas of neurological disorders with the WHO, which has been an important source document for planners and policy makers. Raad Shakir, Secretary General to the WFN, chairs an expert committee on the International Classification of Diseases (ICD-11). The subcommittee on cerebrovascular diseases is chaired by Bo Norrving and one of its members is the author. For the first time we are able to reclassify stroke from being a cardiovascular disease to being a brain disease. The effort continues to have dementia classed as a neurological disorder rather than a "mental disorder".

\section{Brain Year}

The European Brain Council headed by its President Mary Baker (UK) will launch a brain year in 2014. This is to celebrate the creativity, vitality and essentiality of the brain in all human endeavors and the need for a healthy brain. Tentatively three of the major communications will be by Sir Colin Blakemore, a neuroscientist, from a long time prisoner who was deprived of writing instruments and wrote a book in his head and by an Olympic sports champion, emphasizing that sports require not only brawn but brains.

The hope is that 2014 will be the Brain Year in Europe, among its highlights will be the construction of a traveling giant brain. The year 2015 will become the Year of the Brain in the Americas and 2016 the Year of the Brain in Asia.

\section{Collaborations}

Vice President Werner Hacke (Germany) has organized a network of subspecialty brain organizations at an international level. The founding meeting took place at the World Congress in Marrakesh in 2011 and this is being followed up by a survey identifying areas of mutual collaboration.

This effort has been complemented by the Chair of the Applied Research committee, Donna Bergen (USA), who has updated and reorganized the historical "research groups". A few have faded while others have grown and become independent such as the Parkinson's group, yet others have been created to address emerging areas in neurology such as the outcomes and the palliative care groups.



Figure 2: The author at the time of the meeting of the Executive of the WHO, Geneva, January 2013. 


\section{Standards}

As the organization represents world neurology, it is important that anything bearing our logo should stand for its mission and for quality. Consequently we have created an Evaluation and Standards Committee chaired by Aksel Siva (Turkey), Sarosh Katrak (India) and Charles Warlow (UK) initialy and now Werner Hacke (Germany). Organizations, congresses and meetings are welcome to seek our endorsement, but the standards are high. One criterion requires that congresses or meetings seeking our endorsement should be to the benefit of members or patients. We do not endorse congresses or meetings that are held for the profit of the organizers.

\section{Education Committee}

The Education Committee has become the largest and most active committee of the WFN. It is headed by Stephen Sergay (US) and Wolfgang Grisold (Austria). They have a number of innovative programs, including a subcommittee on Electronic Learning. This is chaired jointly by Morris Freedman (Canada) and Riadh Gouider (Tunisia). This committee has also been joined by some young neurologists, savvy in the ways of the electronic world and who have each made a commitment to making global neurology a career. We expect that many good things will result from the Education Committee and its initiatives and the committee will serve as a reference point for accrediting programs and for providing certifications that may help out colleagues in different parts of the world to receive recognition in their respective countries.

\section{Grassroots Grants}

Another decision of the current administration is that we have limited resources and want to apply them to the maximum effect hence it is important that we develop criteria for our activities. We instituted a grants program whereby members of the WFN can apply for projects that are of low cost and high impact, which were judged by the following criteria:

Value - what is the return for invested effort, funds or time? (Priority will be given to low cost, high impact projects);

Viability - Is this a limited time project with a measurable outcome or is it an initiative that will grow and become institutionalized? If the latter, who will take over responsibility after the WFN's initial involvement?

Synergy: a) within the WFN - among Committees, Initiatives and Task Forces, b) with outside partners, governmental and non-governmental organizations, the WHO, funding agencies, etc.; c) potential for publicity and fundraising, viability, synergy and evaluation;

Evaluation - How will the outcome be measured?

In the first competition, the WFN supported all the projects by itself. For the 2012 competition, we invited leaders of other brain organizations to be part of a committee and as a result half of the projects are co-funded by the WFN and other brain organizations. It also has meant that we can find larger projects together.

A new competition is now open.

\section{Publications}

World Neurology moved online to allow for better communication and more features under the leadership of Donald Silberberg (USA), who began his tenure in January 2013.

We thank Mark Hallett and Johan Aarli, the immediate past editors, for having brought World Neurology to a level that allows it to become an interactive online publication.

The Journal of Neurological Sciences has enjoyed a steady increase in its impact factor, readership and circulation under the leadership of Robert Lisak (USA) who has been the Editor for 15 years and who has done so with great devotion and success. A heartfelt "thank you" from all neurologists! Beginning on July 1, 2013, the new Editor will be John England (USA). The journal will emphasize global neurology, outcomes research and best practices.

\section{Communications}

We are working to make the committees more active by instituting regular virtual meetings that will be organized at regular intervals by the central office, minutes will be recorded in a standardized manner and this will serve as an ongoing record of activity. A database of all the minutes will be searchable so that one can know at any given time, what the WFN is doing. This will also serve as the organization's archives.

\section{Fostering New Leaders}

We have made an effort to involve individuals in all stages of their career. As Vice President, the author facilitated the formation of a young neurologists section of the WFN. He has been very encouraged by several young people who want to make global neurology their career. They are devoted, familiar with modern learning and teaching techniques and it is likely that they will reshape to the greatest and most desirable extent, the nature of the WFN.

It has been traditional that all committee chairs and members are appointed for a four year period, the duration of the presidency. We decided to divide the term into two 2 year halves. In the first two years the committees were kept small in order to create a sense of mission given our expanded mandate and to allow for members to get to know each other. For the second two years the committees were enlarged and appointments were made of a number of vice chairs of committees. Typically the vice chairs are younger, from different parts of the world and include more women so that the members of the younger generation have an opportunity to show their leadership qualities. The idea of appointing an individual for two years also helps us identify those who have distinguished themselves so that they can begin to work at a higher level for an additional two year period.

We strive to make the WFN the one brain organization that attracts, involves and nurtures neurologists of all ages, origins, career stages and interests. We are not there yet, but we are on our way!

Vladimir Hachinski Western University, London, Ontario, Canada Email:vladimir.hachinski@lhsc.on.ca 